
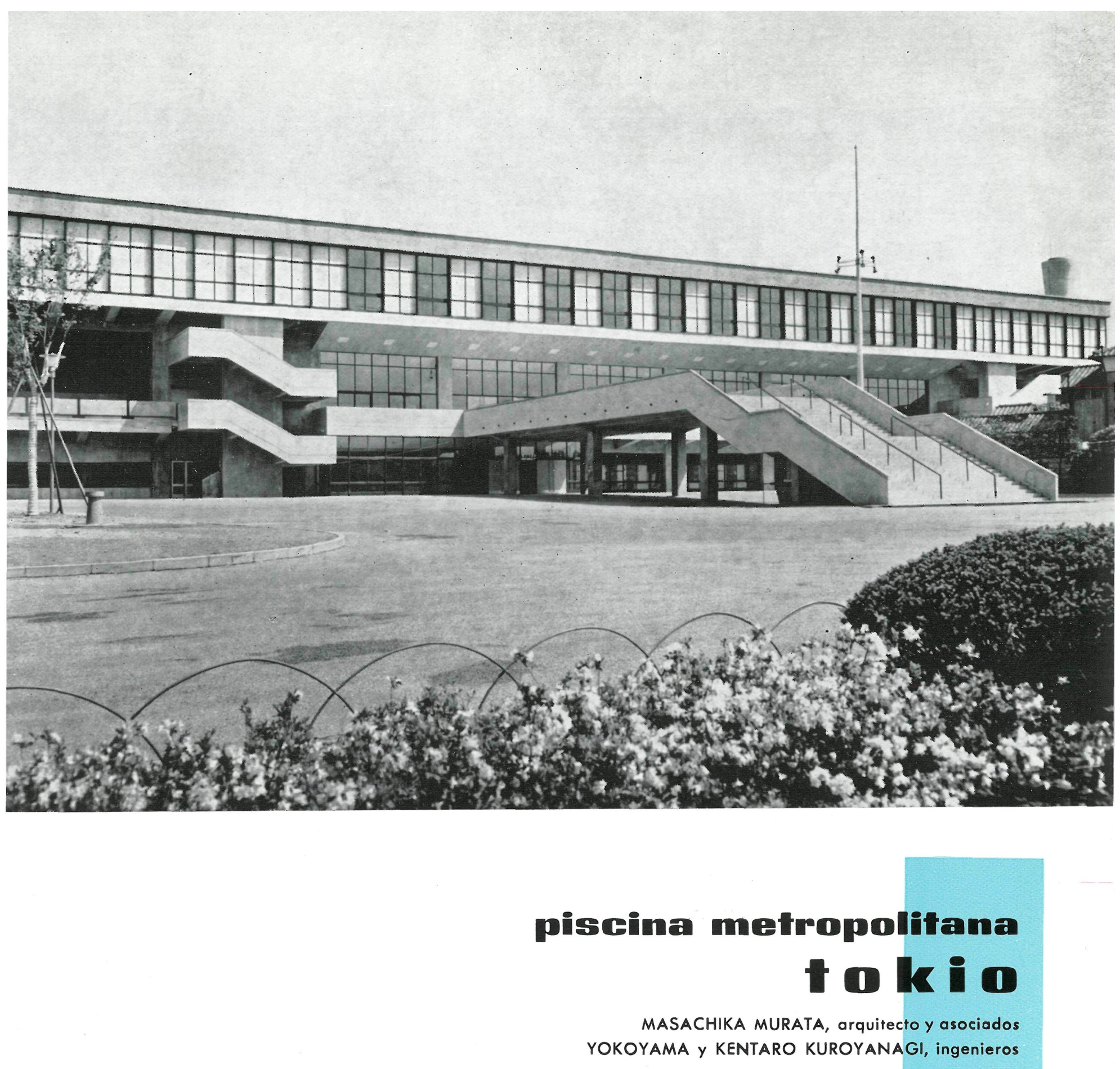

$151 \cdot 24$

Para el proyecto de la piscina metropolitana de Tokio, dedicada a obtener una continuación anual de los deportes acuáticos en sus distintas modalidades y competiciones oficiales, así como solaz y recreo continuado durante todo el año en un recinto cerrado, se han tenido en cuenta las siguientes consideraciones:

a) La tribuna para espectadores se situó a un lado, dejando los otros tres libres para poder levantar unas cristaleras que aseguraran la iluminación natural y permitieran mantener una circulación ordenada de espectadores, personal oficial y atletas durante las competiciones, así como a los usuarios en general durante las horas dedicadas al público. La piscina propiamente dicha se ha separado del recinto de buceo por propio deseo de los practicantes de estos deportes. 


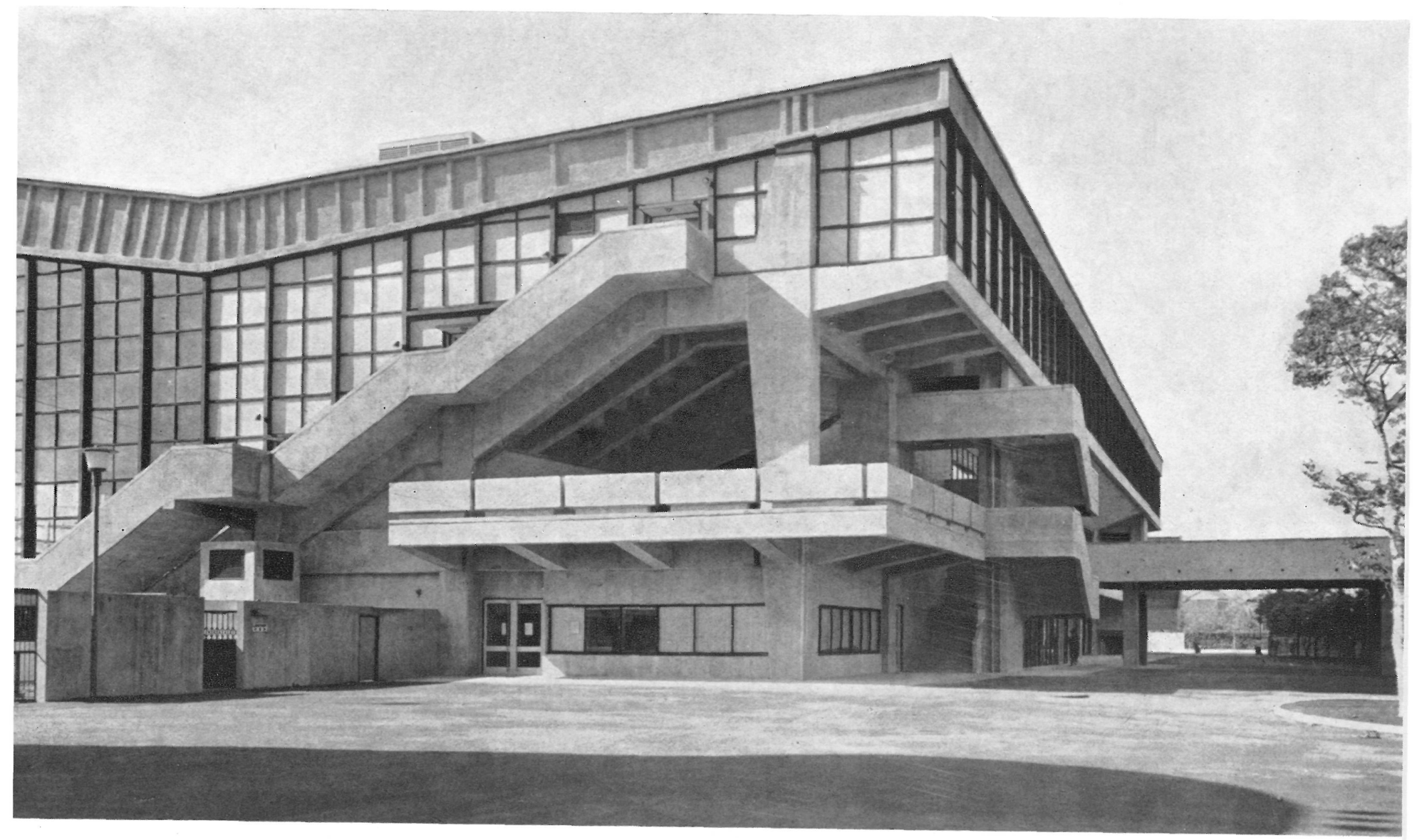

b) Se consideraron de mayor interés los siguientes datos, en lo que se refiere a la forma que el edificio debía tener: 1) El volumen de la piscina y tribuna debía ser el menor posible; 2) Dar gran visibilidad y altura suficiente para las palancas y trampolines, y, finalmente, lograr las mejores condiciones acústicas.

El acondicionamiento del aire y agua sólo se necesita durante ocho meses en el año, período en el que ha de funcionar la ventilación. El interés en reducir el volumen tiene origen en la reducción de los gastos de conservación.

c) Como estos tipos de edificios necesitan disponer de espacio libre sin soportes u otro tipo de entorpecimientos, la estructura presentaba un problema por ser de consideración las dimensiones en planta de la superficie que se tenía que cubrir.

Entre los distintos tipos de estructuras que se estudiaron para cubrir el edificio se eligió una que consiste, en esencia, en una serie de cerchas de forma poligonal, aporticadas, metálicas, que se han articulado en sus dos extremidades.

Esta estructura da una gran libertad para adoptar cualquier tipo de cerramiento y, además, permite la preparación simultánea de los materiales de cerramiento e interiores, lo que se traduce en una disminución del período de ejecución. 

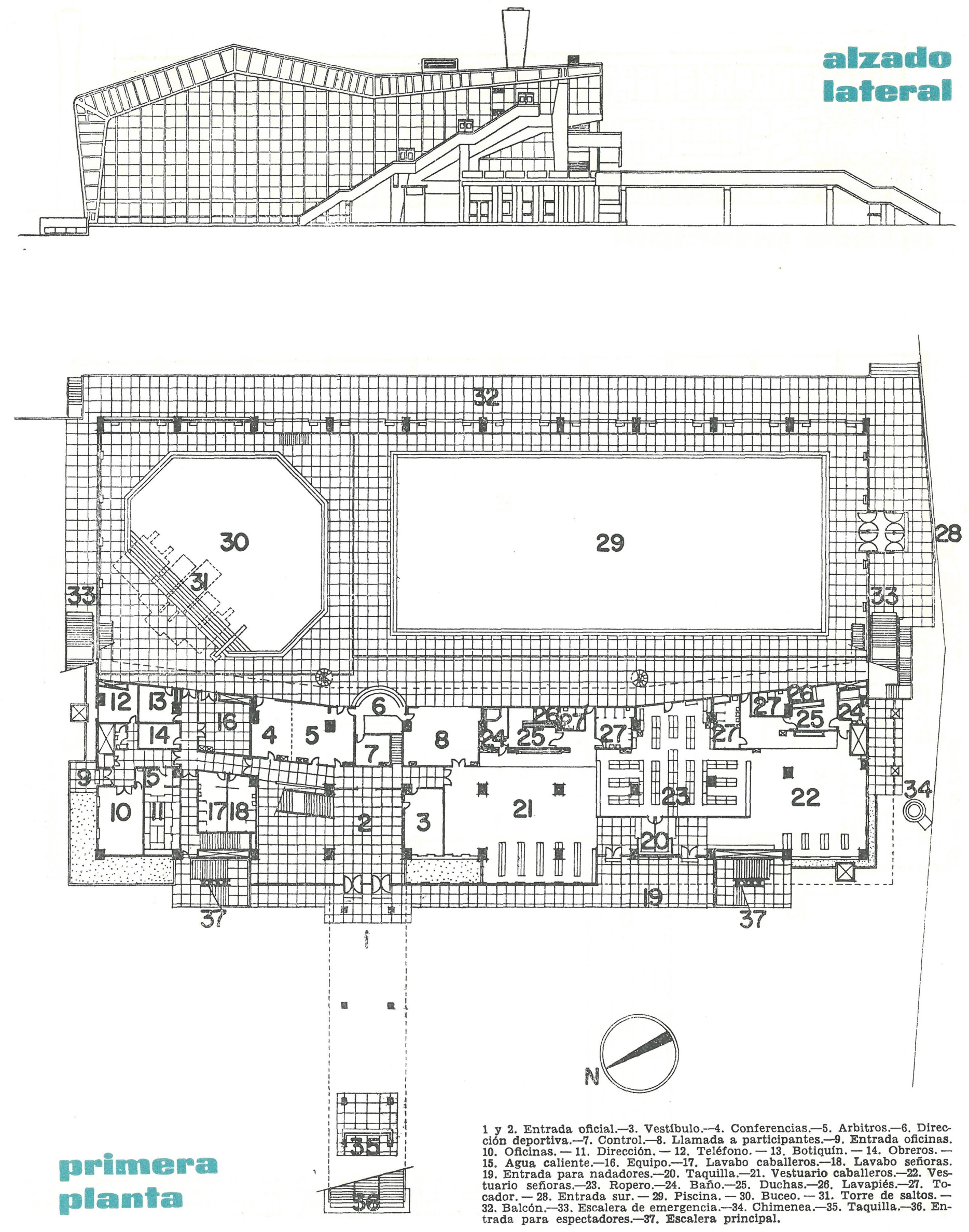


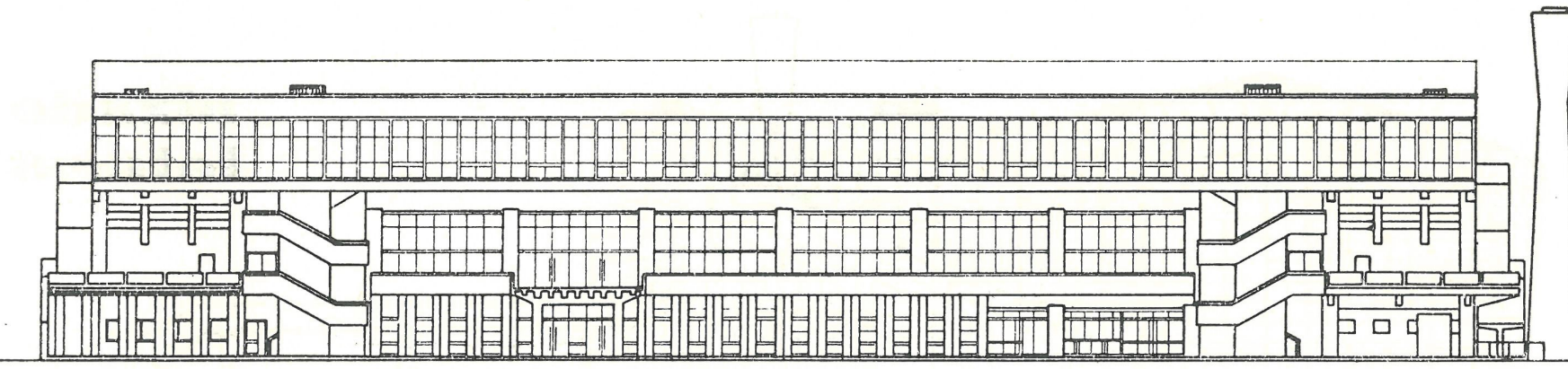

\section{alzado principal}

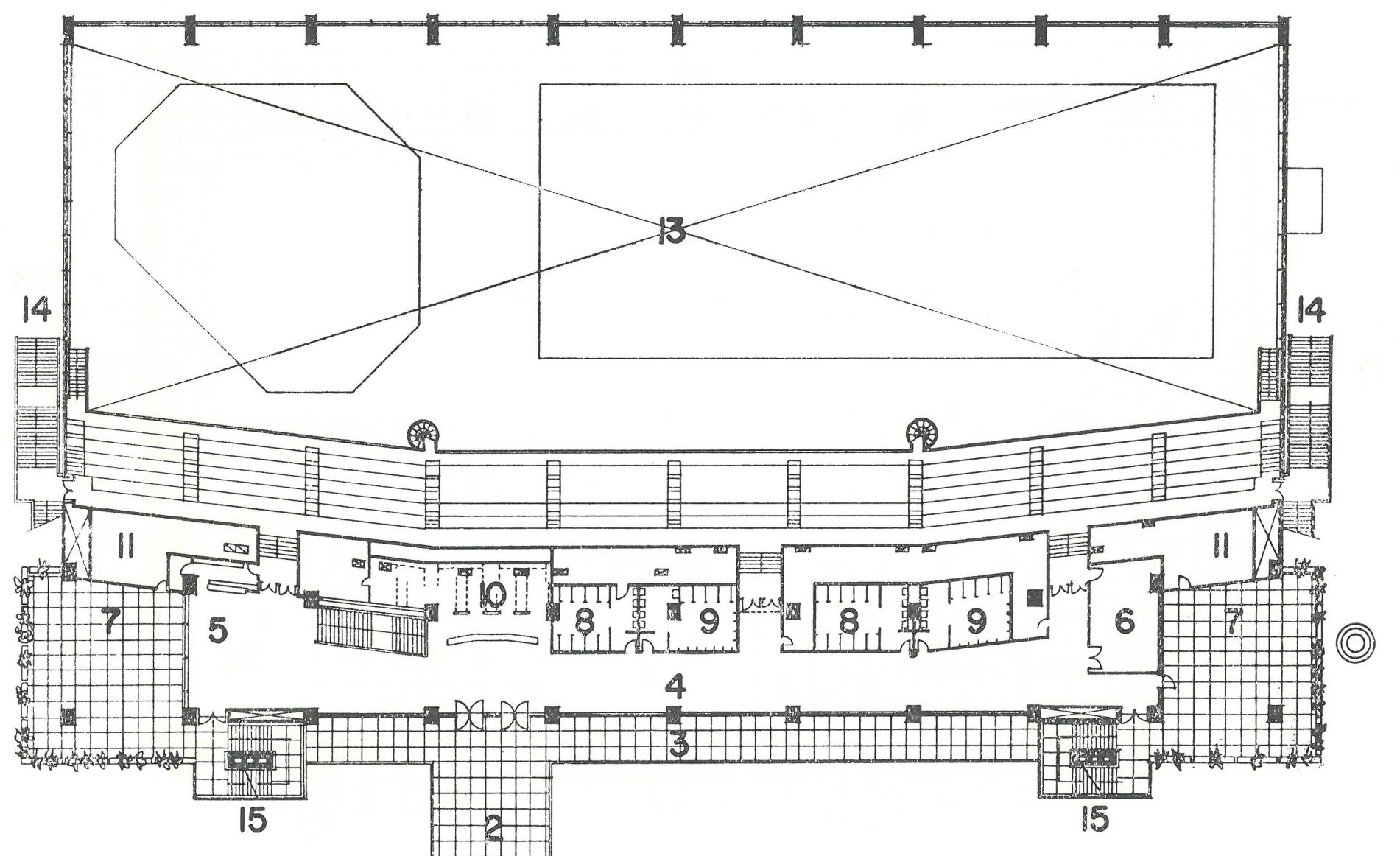

\section{Segurinda plamina}

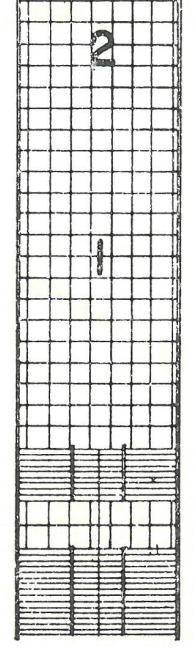

1. Salida de emergencia.-2. Entrada para espectadores.-3. Balcón.-4. Vestíbulo.-5. Bar. -6. Sala de reuniones. -7. Balcón. - 8. Lavabo señoras. - 9. Lavabo caballeros. -10. Vestuario.--11. Ventera de emergencia.-15. Escalera. 
La estructura adoptada tiene su influencia en cimientos, particularmente en las zonas afectadas por los soportes, pero permite, en muchas otras, que los cimientos se hallen en consecuencia con las cargas que han de soportar.

Debido a la forma aporticada, su adaptación a esfuerzos horizontales o empujes es muy apropiado, y únicamente se deja sentir su influencia en las zonas afectadas por momentos flectores.

\section{Instalaciones}

En estos tipos de edificios, destinados al público en general, las instalaciones tienen siempre una gran importancia, pero en este caso viene aumentada, debido a la fuerte evaporación del agua, la condensación y la ventilación necesaria. Otra particularidad es la necesidad de una serie continuada de operaciones de filtraje y depuración del agua.

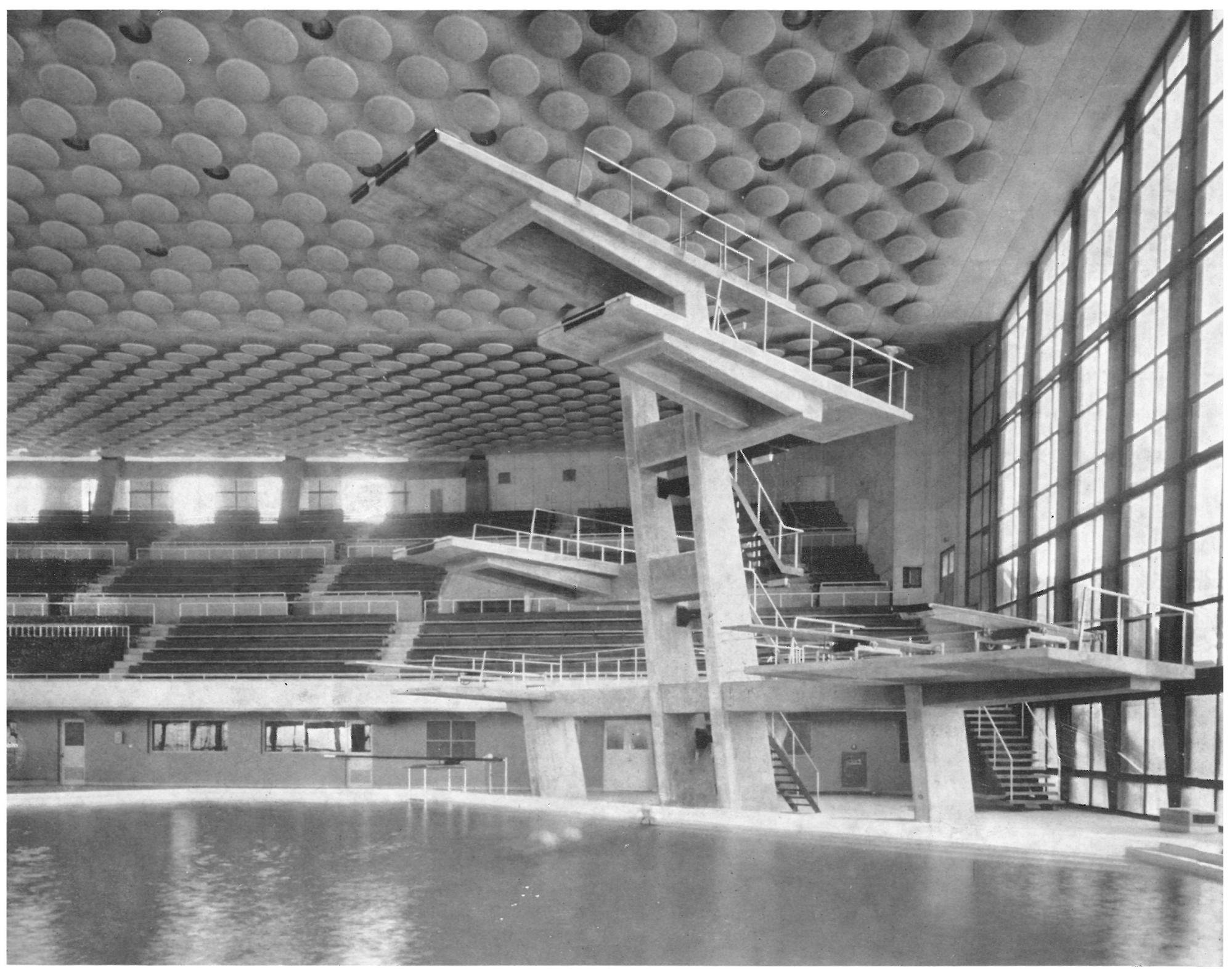


Para luchar contra la condensación se ha establecido un fuerte tiro de ĺa ventilación y mantener el interior a $24^{\circ} \mathrm{C}$, temperatura que es la del agua, de acuerdo con las exigencias en las competiciones oficiales acuáticas.

El agua de la piscina se calienta por medio de un serpentín conectado con una caldera de vapor. El ambiente interior se regula con una instalación de aire acondicionado y el agua experimenta un filtrado completo en un tiempo mínimo de $5 \mathrm{~h}$ para las $1.700 \mathrm{t}$ de agua en la piscina y de $1.500 \mathrm{t}$ para el recinto de buceo; pero en condiciones desventajosas, este tiempo llega hasta 8 horas.

La alimentación de agua en el interior y servicios se efectúa por medio de bombeo de depósitos inferiores a otros superiores, de donde sale por gravedad. La toma de agua se realiza de la red urbana de suministro por medio de una tubería de $0,20 \mathrm{~m}$ de diámetro.

Aparte de las instalaciones mencionadas, existen otras complementarias mecánicas, eléctricas, electrónicas y de depuración.
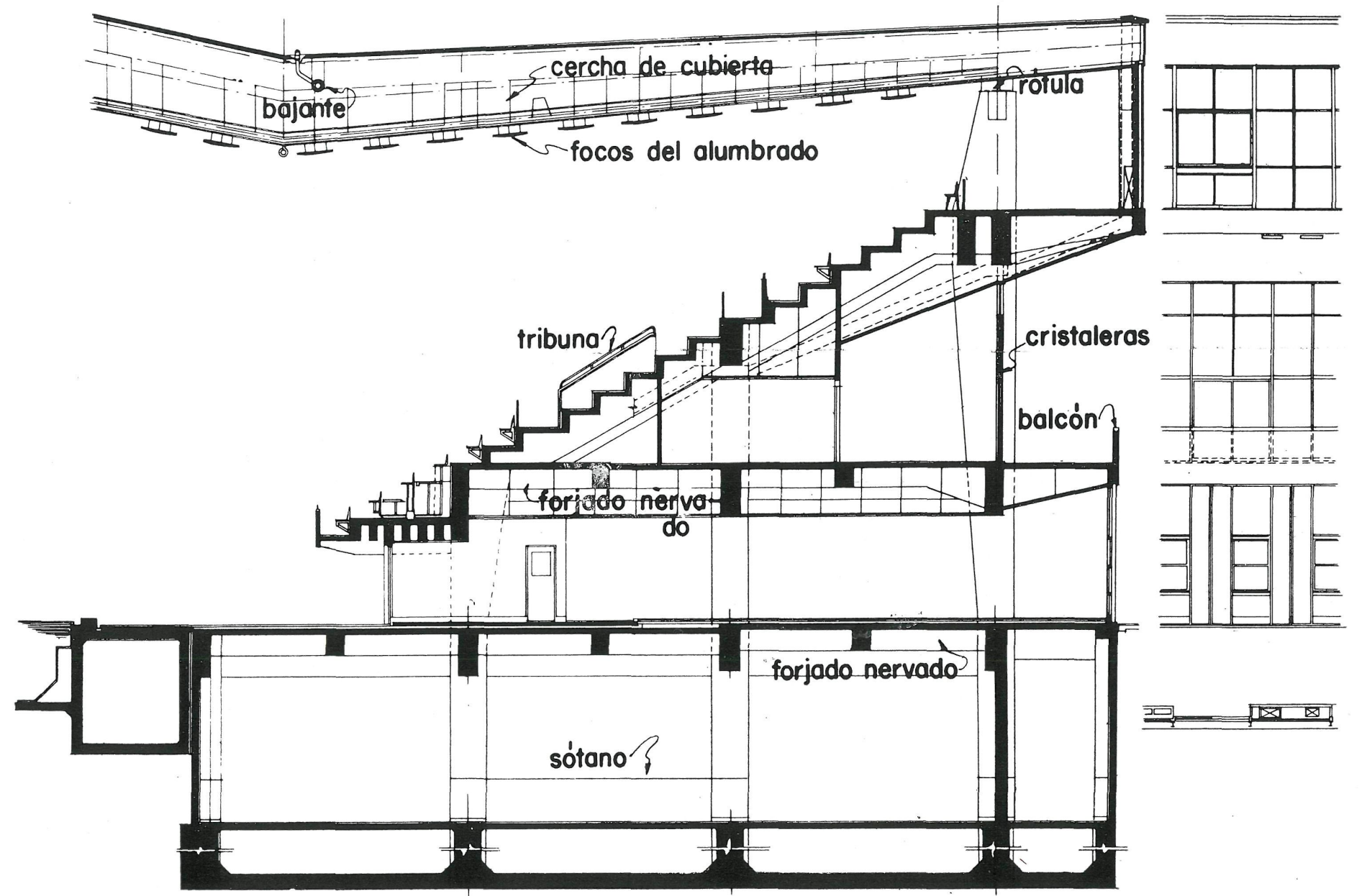